\title{
Coupling hydrodynamic and individual-based models to simulate long- term larval supply to coastal nursery areas
}

\author{
Sébastien Rochette ${ }^{1,2,{ }^{*}}$, Martin Huret $^{2}$, Etienne Rivot $^{1}$, Olivier Le Pape ${ }^{1}$ \\ ${ }^{1}$ UMR 985 Agrocampus Ouest - Inra 'Ecologie \& Santé des Ecosystèmes', Ecologie halieutique, \\ ${ }^{2}$ Département Dynamiques de l'Environnement Côtier, IFREMER, BP 70, 29280 Plouzané, France \\ *: Corresponding author : S. Rochette, email address : sebastien.rochette@ifremer.fr
} Agrocampus Ouest, 65 rue de St Brieuc, CS 84215, 35042 Rennes, France

\begin{abstract}
:
For many marine fish species, recruitment is strongly related to larval survival and dispersal to nursery areas. Simulating larval drift should help assessing the sensitivity of recruitment variability to early life history. An individual-based model (IBM) coupled to a hydrodynamic model was used to simulate common sole larval supply from spawning areas to coastal and estuarine nursery grounds at the population scale in the eastern Channel on a 14-yr time series, from 1991 to 2004. The IBM allowed each particle released to be transported by currents from the hydrodynamic model, to grow with temperature, to migrate vertically giving stage development, and possibly to die according to drift duration, representing the life history from spawning to metamorphosis. Despite sensitivity to the larval mortality rate, the model provided realistic simulations of cohort decline and spatio-temporal variability of larval supply. The model outputs were analysed to explore the effects of hydrodynamics and life history on the interannual variability of settled sole larvae in coastal nurseries. Different hypotheses of the spawning spatial distribution were also tested, comparing homogeneous egg distribution to observation and potential larval survival (PLS) maps. The sensitivity analyses demonstrated that larval supply is more sensitive to the life history along larval drift than to the phenology and volume of spawning, providing explanations for the lack of significant stock-recruitment relationship. Nevertheless, larval supply is sensitive to spawning distribution. Results also suggested a very low connectivity between supposed different sub-populations in the eastern Channel.
\end{abstract}

Keywords: eastern Channel; hydrodynamic model; individual-based model; larval supply; nursery grounds; recruitment variability; Solea solea 


\section{Introduction}

As marine fish species generally produce a high number of eggs with a low probability of survival (Juanes, 2007), small changes in survival rates during early life may cause large variations in recruitment (Daewel et al., 2011). A thorough exploration of survival at successive early life stages is necessary to understand fish population dynamics (Levin and Stunz, 2005). In particular, for a large proportion of commercial marine fish species, stock recruitment relationships are challenged and a better knowledge of recruitment processes would improve our understanding of population dynamics and contribute to a better stock assessment (Brunel and Boucher, 2007).

Estuaries and coastal waters are of major importance for many marine species, especially because they host nursery grounds (Beck et al., 2001). Their carrying capacity influence juvenile fish abundance thus population renewal (Rijnsdorp et al., 1992; Gibson, 1994; Iles and Beverton, 2000; Juanes, 2007). Recruitment and population dynamics of coastal and estuarine dependent species also rely on processes generating high variability in early life stages and especially larval supply driven by hydro-climatic conditions (van der Veer et al., 2000; Houde, 2008). A better understanding of larval processes would help estimating the number of larvae successfully reaching nursery grounds, identifying factors generating the associated spatio-temporal variability and their consequences for recruitment to juvenile stages, as well as population dynamics and structure.

Larval drift individual based models (IBM) have proven useful to investigate the influence of hydrodynamics on ecology of fish larvae, with promising perspectives of integration in fishery management (Hinrichsen et al., 2011). They have been used to identify spawning areas (Walsh et al., 1996), drift duration (Bonhommeau et al., 2009), vertical migration behaviour (Fox et al., 2006; Sentchev and Korotenko, 2007), dispersal kernels (Koutsikopoulos et al., 1991; Ellien et al., 2000, 2000; Sentchev and Korotenko, 2005; Huret et al., 2010) or connectivity within a meta-population (Savina et al., 2009). However, most of these studies were conducted on relatively short periods of time and limited spatial scales. The use of numerical simulations over longer time series at the population scale could provide useful tools to study spatio-temporal recruitment variability generated at larval stages for estuarine and coastal nursery dependent species (Bonhommeau et al., 2009).

The common sole of the eastern Channel (International Council for the Exploitation of the Seas, ICES, division VIId, Fig. 1) is an important commercial flatfish resource, managed as a unique stock. In the eastern Channel, the common sole spawns in early spring, pelagic larvae dwell during several weeks and newly metamorphosed individuals settle in coastal and estuarine areas, acting as exclusive nursery grounds for about 2 years, before sexual maturity (Riou et al., 
2001). Recruitment variability is high (Le Pape et al., 2003) and appears not synchronous among the different nursery areas (Riou et al., 2001), hence suggesting a possible high influence of hydro-climate on larval transport and larval supply.

$<$ Fig. $1>$

To explore the potential effects of hydrodynamics and life history from spawning to metamorphosis on the number of settled sole larvae over nurseries and the associated spatiotemporal variability, larval supply in the different nursery grounds of the eastern Channel was simulated using a three dimensional hydrodynamic model. An individual based particle-tracking module was used to simulate larval drift and survival under realistic biological processes from egg to benthic settlement on estuarine and coastal areas. The sensitivity of larval supply to spawning phenology, larval drift and mortality was assessed at both the nurseries and population scales and the consequences on population dynamics and sub-populations structure were analysed.

\section{Materials and methods}

\subsection{Outlines of the model}

The ultimate objective was to simulate larval supply in different coastal and estuarine sectors (Riou et al., 2001; Rochette et al., 2010) of the eastern Channel (Fig. 1). The approach combined a hydrodynamic model with a particle-tracking module including behaviour to simulate spawning and hatching of eggs, larval drift, growth and settlement on coastal and estuarine nursery grounds under realistic hydro-climatic conditions (Fig. 2). Particles were released following the characteristics of the spawning season and spatial distribution of eggs. The development (growth), swimming behaviour, benthic settlement and survival of each individual (Fig. 2) were modelled in parallel with its transport in the oceanographic model.

$<$ Fig. 2 $>$

\subsection{A hydrodynamic model coupled with a particle-tracking module}

The three dimensional (3D) ocean circulation model MARS (hydrodynamic Model for Application at Regional Scale; Lazure and Dumas, 2008) was used to simulate hydrodynamics in the (western and eastern) Channel during 14 years (1991 - 2004). The model used a $2 \mathrm{~km}$ horizontal resolution with 30 vertical sigma layers. The eastern Channel is about $35000 \mathrm{~km}^{2}$ with an average depth of $35 \mathrm{~m}$ and a maximum of $100 \mathrm{~m}$. A time step of about 2 minutes allowed the 
model to solve the strong tidal currents occurring in the Channel, with respect to stability criteria. River discharges and atmospheric forcing were similar to those in Huret et al. (2010), with interannual variability at open boundaries for temperature and salinity provided by a global circulation model solution ORCA from the OPA-NEMO model (Michel et al., 2009). The simulation period 1991-2004 was the longest allowing for consistent available forcing conditions (river, open boundary and atmospheric).

A particle-tracking module was coupled on-line to the 3D hydrodynamic model with a random-walk to account for vertical turbulent mixing as in Huret et al. (2010). This module included an individual-based modelling framework simulating trajectories and life traits of released particles (Ayata et al., 2010), from spawning areas to nursery grounds (Fig. 2).

The results of the model depend upon $(i)$ initial conditions, i.e. how particles are released (as eggs) in time and space; (ii) behaviour and mortality during the drift. Influences of the spatiotemporal variability of spawning and of the natural mortalities were implemented in a posttreatment analysis by applying a posteriori weighting factors to released particles (Fox et al., 2006). Indeed, each particle released in a specific year $(y=1, \ldots, n)$, date in the year (in Julian day, $\left.t_{r}\right)$, and point of release in the $3 \mathrm{D}$ grid $\left(s_{r(3 D)}\right.$, noted $\left.s_{r}\right)$ represented a certain number of eggs having the same initial conditions $N_{0}\left[y, t_{r}, S_{r}\right]$. Besides, a survival probability was calculated for each particle at the end of the simulated trajectory. The $N_{o}\left[y, t_{r}, s_{r}\right]$ individuals associated with each trajectory were limited by this survival probability during the different eggs and larval stages (Fig. 2) to estimate the number of surviving larvae settling in and outside the nursery grounds (Fig. 1).

\subsection{Initial conditions: spatial and temporal variability of egg release}

Initial number of particles and vertical distribution - To assess the influence of the spatiotemporal distribution of spawning, a trade-off was found between constraints of computing time and frequency and number of particles release that well represents the interannual variability. Different frequency and number of particles were tested. A patch of particles covering the entire eastern Channel was finally released every 15 days during the whole spawning season, from February to June (Anon., 1993), with particles released 1 cell out of 4 on the whole 2D model grid $\left(\mathrm{S}_{\mathrm{r}(2 \mathrm{D})}\right)$. Koutsikopoulos et al (1991) observed eggs over the whole water column at stage 1 but mainly just below surface for stage 2 and 3 (Fig. 3b), suggesting a buoyancy effect. Accordingly, a particle was released each meter from 0 to 5 meters, giving 5 particles at each location $\mathrm{S}_{\mathrm{r}(2 \mathrm{D})}$. Around 9000 particles were released for each year simulated. 
Each particle represents a number of eggs $\left(N_{o}\left[y, t_{r}, s_{r}\right]\right)$ depending on $(i)$ the total number of eggs spawned each year, $N_{\text {eggs }}(y)$ and (ii) the spatio-temporal distribution of eggs in the eastern Channel, included as a weighting factor, $W_{\text {time,space }}\left[y, t_{r}, s_{r}\right]$ :

$$
N_{0}\left[y, t_{r}, s_{r}\right]=N_{\text {eggs }}[y] \cdot W_{\text {time }, \text { space }}\left[y, t_{r}, s_{r}\right]
$$

Interannual number of eggs - The total number of eggs released each year in the eastern Channel $\left(N_{\text {eggs }}[y]\right)$ was calculated as:

$$
N_{\text {eggs }}[y]=\sum_{a}\left(N_{\text {adults }}[a, y] \cdot \operatorname{Pf}[a] . \operatorname{Ew}[a, y] . \operatorname{Pm}[a]\right)
$$

where $N_{\text {adults }}$ is the number of adults of age $(a)$ in year (y) (ICES, 2010), $P f$ the female fraction, Ew the number of eggs per female and $P m$ the proportion of mature females $(0 \%$ until age 2 and $100 \%$ after; ICES, 2010). The proportion of female was calculated from a logistic regression:

$$
P f[a]=1 /\left(1+\exp \left|-\left(a_{P f} \cdot a^{2}+b_{P f} \cdot a+c_{P f}\right)\right|\right)
$$

with parameters $a_{P f}=-2.79 \mathrm{E}-3, b_{P f}=1.58 \mathrm{E}-1$ and $c_{P f}=-4.10 \mathrm{E}-1$ derived from van Beek (1988).

The numbers of eggs at age $(E w)$ were calculated from the number of eggs-at-weight relation (Anon., 1992) and the yearly weights-at-age observed for the eastern Channel population (ICES, 2010).

Weighting factors - Each patch of particles released every 15 days along the spawning period represented a proportion of the total number of eggs spawned in a year $\left(W_{\text {time }}\left[y, t_{r}\right]\right)$, and was distributed in space $\left(W_{\text {space }}\left[t_{r}, s_{r}\right]\right)$. The spatio-temporal weighting factors $W_{\text {timespace }}\left[y, t_{r}, s_{r}\right]$ were the combination of time and space weighting factors, standardized to 1 , such that the sum of weighted particles released each year equalled the number of eggs spawned on this year:

$$
W_{\text {timespace }}\left[y, t_{r}, s_{r}\right]=\frac{W_{\text {time }}\left[y, t_{r}\right] \cdot W_{\text {space }}\left[t_{r}, s_{r}\right]}{\sum_{t_{r}, S_{r}}\left(W_{\text {time }}\left[y, t_{r}\right] \cdot W_{\text {space }}\left[t_{r}, s_{r}\right]\right)}
$$

Time weighting factor $-W_{\text {time }}\left[y, t_{r}\right]$ were calculated using an index of the daily number of eggs spawned varying among years, noted $\alpha_{\text {time }}\left[y, t_{r}\right]$ :

$$
W_{\text {time }}\left[y, t_{r}\right]=\frac{\alpha_{\text {time }}\left[y, t_{r}\right]}{\sum_{t_{r}} \alpha_{\text {time }}\left[y, t_{r}\right]}
$$

In the eastern Channel, the sole spawning period starts in February - March when sea surface temperature reaches $7^{\circ} \mathrm{C}$ (Fonds, 1979) and ends in June (Fig. 2) with a spawning peak in April - 
May (Anon., 1986, 1992, 1993; van Beek, 1988) correlated to sea surface temperature (van der Land, 1991). For each year, a dome shaped curve was defined from a model established on the egg survey conducted in 1991 by the UK Centre for Environment, Fisheries and Aquaculture Science (CEFAS; Anon., 1992). The daily number of eggs in $1991(\psi(t))$ was fitted with a parabolic equation on the log scale:

$$
\log (\psi(t))=a_{p}+b_{p} \cdot t+c_{p} \cdot t^{2}
$$

where $t$ is the Julian day and the estimated parameters $a_{p}=-1.288, b_{p}=0.217$ and $c_{p}=-0.001$.

From Eq. (6), the spawning peak in 1991 occurs on Julian day 110 (April 20 $0^{\text {th }}$ ). In the 3D numerical model, the mean sea surface temperature on the spawning zone at this date was $9^{\circ} \mathrm{C}$, consistent with the estimate of Anon. (1992). Following this, for each year, the spawning peak was defined as the Julian day with maximum proportion of sea surface temperature between 8.5 and $9.5^{\circ} \mathrm{C} . \alpha_{\text {time }}\left[y, t_{r}\right]$ were calculated by translating the dome-shaped curve established in Eq. (6) with regards to the estimated spawning peak.

Spatial weighting factor - The spatial weighting factors $W_{\text {space }}\left[t_{r}, s_{r}\right]$ standing for the spatial and vertical (3D) distribution of eggs were considered constant over years but varied along the spawning season. The single sole egg survey sampling the entire eastern Channel was conducted in 1991 (Anon., 1992), monthly from March to June. Other surveys (Anon., 1986; Grioche et al., 1999) sampled only the eastern half of the area. Eastwood et al. (2001) compiled these data and pointed out that eggs were found over sandy sediments but not on pebbles and rocks (Fig. 3a). Accordingly, no particles were released over coarse sediments. On soft bottoms, the 2D egg distribution $W_{\text {space } 2 D}\left[t_{r}, S_{r(2 D)}\right]$ was derived from kriged maps based on the 1991 egg survey (one for each month). A classical kriging approach was used on log-transformed egg densities with a common exponential variogram (Matheron, 1963; Clark, 1979) and interpolations until a distance of $20 \mathrm{~km}$ (see the average interpolated egg distribution on Fig. 3a). As patches were released every 15 days in the model, particles of intermediate patches were weighted according to the average egg distribution of the previous and the following survey. Patches starting before mid-March were weighed from the first survey and after mid-June from the last one. Finally, the spatial weighting factors were standardized:

$$
W_{\text {space }}\left[t_{r}, s_{r}\right]=\frac{\left.W_{\text {space2D }}\left\lfloor t_{r}, s_{r(2 \mathrm{D})}\right\rfloor / N b_{\text {Particules }} \mid t_{r}, s_{r(2 \mathrm{D})}\right\rfloor}{\sum_{t_{r}}\left(W_{\text {space2D }}\left|t_{r}, s_{r(2 \mathrm{D})}\right| / N b_{\text {Particules }} \mid t_{r}, s_{r(2 \mathrm{D})}\right)}
$$


Further analyses were conducted to validate this spawning pattern, assuming that the spatial distribution of eggs should be close to the distribution of the adult population during the spawning season (Loots et al., 2009). Monthly spatial distributions of catches (French: 57\%, Belgian: $\sim 26 \%$, and English: $\sim 17 \%$ ) for years 2006 to 2008 were provided from the ICES Working group (J. Vigneau, Ifremer, com. pers.). Even if the resolution available for these catch data is large (30' of latitude; $1^{\circ}$ of longitude) and does not show the higher egg production along the coasts (Fig. 3a), their analysis showed that monthly spatial distribution were rather constant among years. Similarly, Loots et al. (2009) pointed out the lack of interannual variations for spatial distribution of the North Sea plaice (Pleuronectes platessa) spawning population. Comparison with the monthly distribution of the 1991 egg survey demonstrated a good overlap in seasonal distribution at the ICES rectangle resolution and suggested the interannual steadiness of the monthly spawning distributions.

$<$ Fig. 3 $>$

\subsection{Life traits of drifting particles}

The status of particles evolves during the drift through 5 successive development stages (Fig. 2): passive transported eggs, passive transported larvae at development stage 1, vertical migrating larvae from stage 2 (Fig. 3b), larvae at metamorphosis and settled larvae (Fig. 2). Transitions between these size specific development stages and mortality rates vary depending on water temperature along trajectories:

Eggs $\rightarrow$ Larvae 1 - Four egg development stages were distinguished (Koutsikopoulos et al., 1991; Fig. 3b). Durations of egg stages are temperature-dependent (see Fonds (1979) for explicit temperature-dependent equations). Eggs are ascending to the surface during the three first development stages using a vertical speed to converge to surface, but are also subject to vertical mixing with the model random-walk. Vertical advection is fully passive for the fourth development stage. The survival of eggs was calculated as $\exp \left(-M_{\text {eggs. }} \Delta t_{\text {eggs }}\right)$ where $\Delta t_{\text {eggs }}$ is the duration of egg stage and $M_{\text {eggs }}$ their mortality rate, related to egg diameter (diam) and temperature encountered by the associated particle (Rijnsdorp and Vingerhoed, 1994):

$$
M_{\text {eggs }}=\exp \left(a_{M}+b_{M} \cdot \operatorname{diam}+c_{M} \cdot \bar{T}\right)
$$

where $\bar{T}$ is the mean temperature during the whole duration of the egg stage; $a_{M}=1.615, b_{M}=-$ $3.517, c_{M}=0.185$. Egg diameter at spawning depended on the time from spawning peak as older females spawn bigger eggs later in the spawning period (size was 1,266 $\mathrm{mm}$ at the spawning 


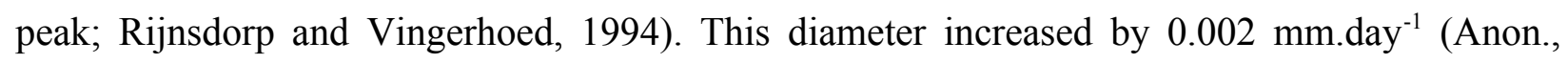
1992). Data used to calculate egg diameter and related mortality for Solea solea in the eastern Channel were issued from Rijnsdorp and Vingerhoed (1994) from an egg survey conducted in 1991.

Larvae $1 \rightarrow$ Metamorphosis - Duration of larval stage 1 is temperature-dependent (see Fonds 1979). Larvae are unable to swim actively during this stage. The length of larvae at the end of stage $1\left(L_{1}\right)$ is modelled following Eq. (9) with parameters $a_{L}=3.528$ and $b_{L}=0.044$ estimated for Solea solea from results of Fonds (1979) and $\bar{T}$ the mean temperature along larval trajectory.

$L_{1}=a_{L}+b_{L} \cdot \bar{T}$

At stage 2, larvae acquire a swimming capacity and go through vertical nycthemeral migration (Fig. 3b; Champalbert et al., 1989, 1992; Koutsikopoulos et al., 1991). The swimming speed is parametrised at 1 body length per second (Gibson, 2005). Such vertical migration is implemented by a depth the particles converge to, using their swimming speed, and is combined to the random-walk of the model. From stage 2 to 4 , larval length at each time step is calculated from Fonds (1979):

$$
L_{t+d t}=L_{t} \cdot \exp \left(g_{L} \cdot d t\right)
$$

where $d t$ is the time step and $g_{L}\left(d a y^{-1}\right)$ the temperature-dependent growth coefficient, a quadratic function of the mean temperature issued from Fonds (1979):

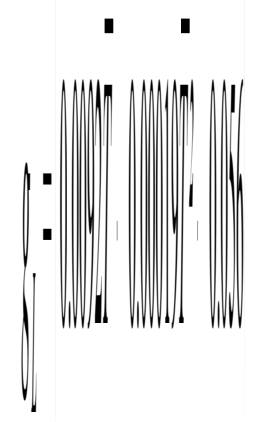

Metamorphosis (Fig. 2) starts when larvae reaches 8.5 mm (Amara and Lagardère, 1995). 
Larval mortality - The survival probability during the larval stages is calculated as exp($\left.M_{\text {larvae. }} \Delta t_{\text {larvae }}\right)$ where $\Delta t_{\text {larvae }}$ is the duration of the entire larval stage until metamorphosis, specific for each trajectory. In the baseline scenario, $M_{\text {larvae }}$ is fixed to 0.04 days ${ }^{-1}$ according to previous estimates for sole (Koutsikopoulos et al., 1991; Horwood, 1993; Lund et al., 2008).

\subsection{Larval settlement and end of simulations}

The aim of the present model was to estimate and analyse the variability of the number of sole larvae reaching nursery grounds in the eastern Channel. From stage 2 to 4 , larvae are able to use a selective tidal stream transport combined to nycthemeral migrations to reach the coasts (Rijnsdorp and Stralen, 1985; Bergman et al., 1989; Amara et al., 1998; Grioche et al., 2000; Forward and Tankersley, 2001; Fox et al., 2006). However, this behaviour only appears when larvae approach settlement zones (Boehlert and Mundy, 1988; Ramzi et al., 2001ab) and no metamorphosed larvae nor juvenile were ever found outside nursery areas (Riou et al., 2001). To avoid the spurious simulation of larval behaviour over coastal areas, the model tested if larvae reach the coastal strip before metamorphosis. Hence, the final destination over the nursery was not targeted and larval supply was only estimated at the large extent of the 6 coastal nursery sectors (Fig. 1) based on juvenile distribution (Riou et al., 2001; Rochette et al., 2010).

In the model, larvae are transported until they reach the coastal area within the $25 \mathrm{~m}$ isobath with a soft bottom (i.e. nursery ground; Fig. 1) or until they reach metamorphosis. If they reach a nursery at stage 2 or higher before metamorphosis, they are considered to settle in this area but the larval mortality is still applied until metamorphosis $(8.5 \mathrm{~mm})$. If they attain metamorphosis outside these coastal sectors, a $0 \%$ survival is applied. This is consistent with the hypothesis that larvae die while reaching size of metamorphosis out of shallow areas, as distance possibly travelled by a metamorphosed larvae outside suitable habitats to reach nursery sectors is low. Indeed, the $25 \mathrm{~m}$ bathymetry limit indirectly accounts for a possible active travelled distance, as the observed limit for juveniles distribution is $20 \mathrm{~m}$ isobath in the eastern Channel (Riou et al., 2001; Rochette et al., 2010).

\subsection{Model outputs: patterns in larval supply to nursery grounds and spatial structure}

Model outputs were first analysed in terms of spawning dynamics, drift duration, cohort decline and number of successful larvae at the population scale. Then, the interannual variability of larval supply was estimated on the different nursery sectors.

The connectivity between spawning areas and nursery grounds was analysed. The individual-based trajectories allowed mapping the Potential Larval Survival (PLS, Daewel et al., 2011), i.e. the probability to reach a nursery for each initial location. Connectivity was also 
analysed by dividing the eastern Channel into three spawning sub-areas (Fig. 3a), based on ( $i$ ) the map of egg distributions and (ii) the presence of a central Channel eastward current (Hoch and Garreau, 1998) which separate English and French coasts. Three spawning sub-areas were defined: the western and eastern part of the French coasts, separated by a rocky central area, and the English coasts (Fig. 3a). Contributions of settled larvae coming from each spawning sub-area were calculated for each nursery.

\subsection{Sensitivity analysis: sources of variability in spatio-temporal larval supply}

Sources of interannual variability in larval supply - Three factors acting at the population scale in the model impact the interannual variability of successful larval abundance: $(i)$ larval mortality, (ii) variability of the spawning peak and (iii) number of eggs released. The relative influence of the survival during transport versus the number of eggs spawned in the interannual variability of larval supply was assessed. This question is of critical importance as this determines the possible observation of the stock-recruitment relationship. The influence of the 3 factors above on the interannual fluctuations of larval supply was tested at the scales of both the whole eastern Channel population and the nursery sectors, while modifying the baseline scenario: $(i)$ As the larval mortality rate $M_{\text {larvae }}$ (in days ${ }^{-1}$ ) was fixed to 0.04 in the model, two other values were tested ( 0.03 and 0.05 ) with regards to literature. (ii) To assess the influence of the spawning peak, a scenario considering a constant spawning rate during the spawning season was tested. (iii) To assess the influence of the spawning stock biomass (SSB) a scenario with constant number of eggs released each year $\left(N_{\text {eggs }}^{\prime}[y]=\right.$ mean $\left.\left(N_{\text {eggs }}[1991-2004]\right)\right)$ was tested.

Sensitivity to spawning distribution - The sensitivity of the larval supply to the spawning distribution was analysed from two alternative scenarios: ( $i$ ) a homogeneous egg distribution, and (ii) an egg distribution according to the PLS map (cf. \$2.6).

Indicators to quantify the level of sensitivity of larval supply to mortality and spawning spatio-temporal dynamics - The sensitivity analysis was performed through two statistics related to interannual recruitment success: $(i)$ the mean bias, mean $\left[\left(N_{\text {larvae_scenario }}(y)-N_{\text {larvae_baseline }}(y)\right) /\right.$ $\left.N_{\text {larvae_baseline }}(y)\right]$, to test for scale factors in larval supply, and ( $\left.i i\right)$ the linear correlation coefficient, $\rho\left(N_{\text {larvae_scenario }}(y) \sim\right.$ Nlarvae_baseline $\left.(y)\right)$, to test for changes in fluctuations among years. These criteria were calculated at both the population and the nursery scales.

Sensitivity of the level of spatial connectivity to model inputs - Connectivity between spawning areas and nursery grounds may also depend on larval mortality, variability in the timing of the spawning peak and spawning distribution. Hence, their influence on the PLS map and the exchanges between the 3 sub-areas (Fig. 3a) was also analysed, using the scenarios described above. 


\section{3. $\underline{\text { Results }}$}

\subsection{General patterns of the simulated larval drift}

The timing of the spawning peak showed a high interannual variability. The estimated peak ranged from mid-March for warm years to the end of April for colder ones. The drift duration, between spawning and metamorphosis, was variable between years, ranging from 51 to 68 days with a mean at 59.5 days. The average of the settlement period took place between mid-May and mid-June (Fig. 4).

$<$ Fig. $4>$

At the population scale, the mean survival, averaged over the 1991-2004 period, from spawning to settlement, estimated with the baseline mortality rate for larvae $M_{\text {larvae }}=0.04$ day $^{-1}$ was 10.5 settled larvae in the eastern Channel for 10000 eggs spawned (Fig. 4, Fig. 5). This low recruitment success at settlement resulted from (i) the high mortality from spawning to metamorphosis (98\% death) and (ii) the high mortality at settlement due to the large proportion of particles undergoing metamorphosis outside nursery grounds ( $95 \%$ death). The latter consisted of particles settling in deep water in the eastern Channel (49\%) or transported outside the study area, in the North Sea (48\%) and in the western Channel (3\%).

The settlement success varied along the season with relation to both the high mortality during the temperature-dependent drift duration and changes in current direction. Average survival increased from 6.6 settled larvae per 10000 eggs at the beginning of the spawning period (patch released $\sim 30$ days before spawning peak), to 11.5 at the end ( $\sim 30$ days after).

The interannual variability of the larval supply was high (Coefficient of Variation, standard error / mean, $\mathrm{CV}=63 \%$ ) during the period 1991-2004 (Fig. 5) with total larval supply (over all nursery grounds) ranging from $1.4 \times 10^{9}$ in 2001 to $9.7 \times 10^{9}$ in 1996 . This variability was correlated to spawning peak as later spawning peak showed a higher larval supply. Although temperature influences drift duration and larval mortality, survival to drift did not explain this correlation. The correlation was mainly due to the probability to reach metamorphosis over a nursery (Fig. 5). Indeed, the loss of larvae in the North Sea was higher for warmer years (54\% of metamorphosis in the North Sea on average for years 1997, 1998, 1999 and 2002) than for colder years (42\% for years 1991, 1992 and 1996). This particularly affected the Somme sector, which proportion in total larval supply is especially high (46\% on average; Fig. 5). The larval supply among the nursery sectors was variable among years with coefficient of variation from $\mathrm{CV}=42 \%$ (U.K. West) to $\mathrm{CV}=150 \%$ (Seine); these fluctuations were not synchronous among nurseries (Fig. 5). 
$<$ Fig $5>$

\subsection{Connectivity from spawning to nursery grounds}

The common sole population of the eastern Channel seems to maximize its success in larval transport when spawning along the English and the eastern French coasts (Fig. 6). However, if observed egg distribution (Fig. 3a) present similarities with PLS maps (Fig. 6), it does not reflect where spawning could potentially result in high levels of early stage survival for two areas: $(i)$ an important spawning area exists in the north of the eastern French coasts, associated with a low or null probabilities to settle on a nursery of the eastern Channel, and (ii) spawning in the Seine estuary is associated with a high probability of settling on a nursery but only a few eggs were spawned there in 1991.

PLS (Fig. 6) supported the influence of the eastward current in the middle of the eastern Channel, separating northern and southern spawning areas (Fig. 3a). The strong relation between the origin of eggs and larval settlement denoted the low connectivity (Fig. 6) between the three sub-areas from spawning to settlement. On average over the period $1991-2004$, almost all the particles settling on a coastal nursery resulted from eggs spawned in the associated spawning area. All the percentages were over $98 \%$ of self-supply, except for one episode in 1995 at $93 \%$ and $96 \%$ for the English and western French coasts respectively, and one in 2002 at $92 \%$ for the eastern French coasts.

$<$ Fig. 6>

\subsection{Sensitivity analysis}

Sensitivity of larval supply to mortalities - Estimates of larval supply were especially sensitive to the mortality rate $M_{\text {larvae }}$. At the scale of the whole population, the mean survival from spawning to settlement ranged from 7.1 per 10000 eggs for $M_{\text {larvae }}=0.05$ day $^{-1}$ to 15.6 per 10000 for $M_{\text {larvae }}=0.03$ day $^{-1}$. Although the mean number of larvae was changed, neither the interannual fluctuations of the larval supply at the scale of the population nor at the scale of nurseries $\left(\mathrm{R}^{2} \approx 1\right.$, Table 1$)$ were sensitive to change in larval mortality; larval mortality appeared as a scale factor for larval settlement success.

Sensitivity of larval supply to spawning dynamics - The sensitivity analysis first showed the low influence of the spawning timing on the total number of successful larvae: when a constant spawning rate was simulated from February to June, settlement success was not biased (Table 1) and had similar fluctuations than in the baseline scenario. This was verified at the scale 
of nurseries, except a positive bias for Seine and Calvados nurseries and a slight change in fluctuations in U.K. West nursery (Table 1).

The scenario evaluating larval supply without interannual variations of the number of eggs spawned revealed that larval settlement success was not sensitive to the spawning biomass variability for a realistic range of variation. A constant spawning biomass did not lead to bias nor changes in fluctuations of larval supply in the eastern Channel nor at the scale of nurseries except for a positive bias for Seine and Calvados nurseries (Table 1).

At the scale of the eastern Channel, model outputs revealed poorly sensitive to the initial spatial distribution of eggs. A homogeneous spatial spawning showed no major differences in larval supply at the scale of the eastern Channel. However, this hides a different allocation of larvae among nurseries (Table 1). Although interannual fluctuations were similar to the baseline scenario, the larval supply was lower in the Somme nursery but higher elsewhere, in particular in the Seine estuary (+203\%; Table 1). When the PLS map (Fig. 6) was used instead of observed eggs distribution, larval supply was higher, with similar interannual fluctuations at both the eastern Channel and the nursery scales (Table 1). Only Calvados and Veys nurseries showed slightly different interannual fluctuations.

Sensitivity of connectivity to model options - The different scenarios revealed only a marginal influence on the PLS map. Larval mortality acted as a scale factor, with a negative relation between PLS and larval mortality but without change in the relative PLS distribution.

At the scale of the 3 sub-areas, the connectivity was not modified when running the different scenarios and remained very low, except when the spatial distribution of spawning was modified. Using homogeneous and PLS map influence the origin of particles reaching the Somme nursery, with respectively $10 \%$ (with 2 episodes of $40 \%$ ) and $5 \%$ mean larval supply from the western French coasts.

$<$ Table 1>

\section{Discussion}

\subsection{Simulating larval recruitment at large spatial and temporal scales}

This modelling approach illustrated the contribution of numerical simulation models to investigate the processes underlying the variability of fish recruitment (Hinrichsen et al., 2011), with a focus on a nursery dependent flatfish species. Simulations on relatively short periods of time were previously carried out to explore the effect of the hydrodynamics and larval behaviour on spatio-temporal mortalities or location of flatfish metamorphosis (Sentchev and Korotenko, 
2007; Korotenko and Sentchev, 2008; Savina et al., 2009). The specificity of the present study consisted in exploring long-term simulations to assess the interannual variability of simulated trajectories. This was possible for flatfish as their life cycle is characterized by a metamorphosis to benthic life (Gibson, 2005) occurring early in the life cycle, before significant active swimming. From metamorphosis, juveniles swim to shallow adjacent nursery grounds (Ramzi et al., 2001ab; Fox et al., 2006), using selective tidal stream transport (Rijnsdorp and Stralen, 1985; Bergman et al., 1989; Amara et al., 1998; Grioche et al., 2000; Forward and Tankersley, 2001; Fox et al., 2006). This behaviour was assumed to maintain larvae over nursery sectors once the $25 \mathrm{~m}$ isobath limit was reached, which drastically simplifies the end of simulations under realistic hypotheses. Indeed, estimating larval supply at the scale of nurseries did not require knowing the exact final destination of larvae but only the nursery sector where settlement occurred. This focus on large scale results $\left(>50 \mathrm{~km}^{2}\right)$, simplifying their analysis, allowed to carry out simulations over several years.

The simulation outputs patterns first confirmed that parameters of the biological model provided realistic life traits during pelagic stages for the common sole population in the eastern Channel. For instance, duration between spawning and settlement, estimated at 59.5 days, was in accordance with previous in situ estimates. Anon. (1993) estimated the time before hatching at "about 8 days" (average of 7.5 days in our study) then the duration of larval pelagic phase at "about 6 weeks" (52 days here). The average survival between eggs and settled larvae estimated from our simulations were low; only 10.5 ( 7 - 16) settled larvae survived for 10000 eggs spawned. This rate was also consistent with previous results for other flatfish population: $\sim 10$ for sole in the Bay of Biscay (Koutsikopoulos et al., 1989, 1991) and for the North Sea plaice (Le Pape and Bonhommeau, sub.).

However, on average, $48 \%$ of sole larvae reach the size of metamorphosis in the North Sea, outside the northern limit set for the eastern Channel population (ICES, 2010). These larvae could settle on northern nursery grounds (Rijnsdorp et al., 1992) and contribute to the North Sea population (Savina et al., 2009). Accordingly, PLS map revealed discrepancies between the low probabilities of success and the high amount of spawning products in the north east of the study area. This could be explained by larvae drifting to the North Sea, not counted as successful settlers in the present studied area thus underestimating the PLS in an important realized spawning area. Moreover, the model boundaries led to overestimate the number of particles reaching metamorphosis in the North Sea. Indeed, if the western limit of the hydrodynamic model was far from the eastern Channel, its north-eastern limit was only $10 \mathrm{~km}$ upper the studied area. As Lagrangian residuals sea currents are eastward in the eastern Channel (Hoch and Garreau, 1998), 24\% of all the particles passed through the north-eastern boundary of the model and were not further simulated. Because of the balanced tidal currents, some of these particles 
would have been able to settle in the eastern Channel if they had not been considered lost with the particle-tracking system. A complementary simulation run with a hydrodynamical model having a further northern limit but a coarser resolution suggested that the number of particles reaching "Rye Bay" could have been higher for some years. Conversely, this loss barely affected other nursery sectors. Thus, simulation outputs can be estimated as reliable, except for the northeastern part of the studied area where they should be considered as a first approach.

In spite of these local underestimation of the PLS, the larval supply model provided realistic simulations of pelagic stages dispersal and realistic levels of mortality at the scale of the eastern Channel sole population. They could be used to estimate the spatial and temporal patterns in larval supply and to identify the driving factors of their variability.

\subsection{The main influence of larval drift on recruitment success}

The huge natural variability in the mortality of young life stages generally hampers the identification of significant stock-recruitment relationships (Brunel and Boucher, 2007; Houde, 2008). The working group in charge of stock assessment of the common sole in the eastern Channel (ICES, 2010) could not identify any clear stock-recruitment relationship and projections are carried out under the hypothesis of a constant mean recruitment, independent from the spawning biomass.

Accordingly, the larval supply model highlighted relative variations of the number of successful larvae to be dominated by larval life history without obvious relation to spawning. Indeed, the sensitivity analysis revealed the low influence of (i) SSB, (ii) spawning peak and (iii) spawning distribution on the relative fluctuations of larval supply at the population scale. Conversely, the probability to reach a nursery at metamorphosis drove larval supply variations in the eastern Channel. At the scale of local nurseries, the interannual variability of larval supply was not synchronous between the different nursery sectors. Such a spatial asynchrony largely results from the interannual variability of the hydrodynamics in the eastern Channel. At the population scale, cold winters were correlated with higher larval supply in the eastern Channel whereas warmer winters showed a more important loss in the North Sea. This may be due to North Atlantic Oscillation (NAO) being higher for warmer winters and leading to stronger currents eastward (Hurrel and van Loon, 1997; Pingree, 2005). A higher NAO and a related warmer winter could lead to higher larval loss to the North Sea. This sensitivity of larval supply to hydrodynamics partly explained the difficulty to identify stock - recruitment relationship for this population. Moreover, although the spawning distribution barely affected the fluctuations of the larval supply, it had a high influence on the average amount of successful larvae over the studied period. The importance of currents and spawning distribution on larval supply pointed 
out the importance of considering larval drift (Werner et al., 1997) to improve understanding of recruitment variability (Hinrichsen et al., 2011). In that perspective, ocean circulation models coupled with individual-based transport systems provide insights on different species strategies (Daewel et al., 2011) and are potential tools for fishery management (Hinrichsen et al., 2009, 2011).

\subsection{Connectivity, meta-population structure}

The present modeling appoach analysed the trajectories of particles from spawning grounds to nurseries and focused on the limited larval dispersion in the eastern Channel, spawning areas feeding adjacent coastal and estuarine nursery grounds without significant exchanges with other regions of the eastern Channel. This new insight about life history during pelagic stages, together with previous analyses on older life stages raised questions about the existence of quite isolated sub-populations at the scale of the eastern Channel: Coggan and Dando (1988) and Anon. (1989) showed that sole juveniles stay over nurseries during their first two years of life. Kotthaus (1963) and Anon. (1965) observed that adult soles remained close to their nursery even after seasonal spawning migration. A mark-recapture survey investigated by Burt and Millner (2008) confirmed the low mobility of adult soles in the eastern Channel: adult soles of the English coasts remained along these coasts, soles of the eastern French coasts could migrate to the English coasts and soles of the western French coasts had only very low migrations. Despite the lack of observed genetic structure within the eastern Channel (Exadactylos. et al., 2003), the low local exchanges between sub-areas at larval stage, combined with previous conclusions on juveniles and adults behaviour, suggested a high level of segregation between sub-populations in the eastern Channel.

This raised the question of the management of the common sole fishery at the scale of the eastern Channel as a single stock (ICES, 2010) and in particular the possible isolation of the western French coasts. A potentially isolated sub population in this sector will be especially sensitive to highly degraded nursery area in the Seine estuary (Gilliers et al., 2006). At the scale of the eastern Channel population, the loss in abundance related to these anthropogenic disturbance for juvenile sole was estimated to be nearly 17\% (15-32\%; Rochette et al., 2010). The influence of habitat degradation on the population renewal would be exacerbated in the case of an isolated sub-population in the western part of the French coast. Habitat degradation could contribute to the choice of spawning areas and potentially explain why low realized spawning production in this sector do not reflect potentially high levels of early larval survival. Indeed, as PLS is high in this sector, both spawning habitat selection (Daewel et al., 2011) and additional mortality during young stages (Gilliers et al., 2006) could be induced by local disturbances and 
contribute to low densities of juvenile sole observed in nursery grounds in the Seine Estuary (Rochette et al., 2010).

\section{Acknowledgements}

This research was founded funding by the European Community's Seventh Framework Programme (FP7/2007-2013) under Grant Agreement No. 266445 for the project Vectors of Change in Oceans and Seas Marine Life, Impact on Economic Sectors (VECTORS). This project was also supported by the French National Agency for Research (ANR, Project SoleBeMol-Pop; Vulnérabilité, Milieux et Climat). We would like to thank Joël Vigneau (Ifremer, Port-en-Bessin, France) for his useful advices and the data of fisheries catches, and A.M. Tréguier for the ORCA model solution for boundary conditions. We also wish to thank the anonymous reviewers who improved this manuscript.

\section{Références}

Amara, R. \& Lagardère, F. 1995. Taille et âge au début de la métamorphose chez la sole (Solea solea (L.)) du golfe de Gascogne. ICES Journal of Marine Science 52:247-256.

Amara, R., Poulard, J.C., Lagardere, F. \& Desaunay, Y. 1998. Comparison between the life cycle of two Soleidae, the common sole, Solea solea, and the thickback sole, Microchirus variegatus, in the Bay of Biscay (France). Environmental Biology of Fishes 53:193-209.

Anon. 1965. Report of the working group on sole. Page 126.

Anon. 1986. Report of the ad hoc working group on the 1984 and 1985 sole (Solea solea L.) egg surveys.

Anon. 1989. Report of the ad hoc working group on juvenile sole tagging. Page 34. Ostende, 10-12 March 1987.

Anon. 1992. Report of the study group on the fecundity of sole and plaice in sub-areas IV, VII, and VIII.

Anon. 1993. Identification biogéographique des principaux stocks expoités en Manche, relations avec ceux des régions voisines RI DRV 93-028:256 p.

Ayata, S.-D., Lazure, P. \& Thiébaut, É. 2010. How does the connectivity between populations mediate range limits of marine invertebrates? A case study of larval dispersal between the Bay of Biscay and the English Channel (North-East Atlantic). Progress In Oceanography 87:18-36. doi: 10.1016/j.pocean.2010.09.022.

Beck, M.W., Heck, K.L., Able, K.W., Childers, D.L., Eggleston, D.B., Gillanders, B.M., Halpern, B., Hays, C.G., Hostino, K., Minello, T.J., Orth, R.J., Sheridan, P. \& Weinstein, M.P. 2001. The role of nearshore ecosystems as fish and shellfish nurseries. bioscience 51:633-641.

van Beek, F.A. 1988. On the growth of sole in the North Sea.

Bergman, M.J.N., Van Der Veer, H.W., Stam, A. \& Zuideman, D. 1989. Transport mechanisms of larval plaice (Pleuronectes platessa L.) from the coastal zone into the Wadden Sea nursery area. P.v. Réun. Cons. int. Explor. Mer 191:43-49.

Boehlert, G.W. \& Mundy, B.C. 1988. Roles of behavioral factors in larval and juvenile fish recruitment to estuarine nursery areas. American Fisheries Society Symposium 3:51-67.

Bonhommeau, S., Le Pape, O., Gascuel, D., Blanke, B., Tréguier, A.-M., Grima, N., Vermard, Y., Castonguay, M. \& Rivot, E. 2009. Estimates of the mortality and the duration of the transAtlantic migration of European eel Anguilla anguilla leptocephali using a particle tracking model. Journal of Fish Biology 74:1891-1914. doi: 10.1111/j.1095-8649.2009.02298.x.

Brunel, T. \& Boucher, J. 2007. Long-term trends in fish recruitment in the North East Atlantic related to climate change.

Burt, G.J. \& Millner, R.S. 2008. Movements of sole in the southern North Sea and eastern English Channel from tagging studies (1955-2004). Page 44. Cefas, Lowestoft. 
Champalbert, G., Bourdillon, A., Castelbon, C., Chikhi, D., Le Direach-Boursier, L., Macquart-Moulin, C. \& Patriti, G. 1989. Migratory determinism of larvae and juveniles of the sole. Oceanis 15:171180. Retrieved September 1, 2010, .

Champalbert, G., Macquart-Moulin, C. \& Patriti, G. 1992. Experimental study of the swimming activity of larval and juvenile sole, Solea solea (L.). Annales de l'institut océanographique 68:89-105.

Clark, I. 1979. The semivariogram-Part 1. Engineering Mining Journal 180:90-94.

Coggan, R.A. \& Dando, P.R. 1988. Movements of juvenile Dover sole, Solea solea (L.), in the Tamar Estuary, South-western England 33:177-184.

Daewel, U., Peck, M.A. \& Schrum, C. 2011. Life history strategy and impacts of environmental variability on early life stages of two marine fishes in the North Sea: an individual-based modelling approach. Canadian Journal of Fisheries and Aquatic Sciences 68:426-443. doi: 10.1139/F10-164.

Eastwood, P.D., Meaden, G.J. \& Grioche, A. 2001. Modelling spatial variations in spawning habitat suitability for the sole Solea solea using regression quantiles and GIS procedures. Marine Ecology Progress Series 224:251-266.

Ellien, C., Thiebaut, E., Barnay, A.-S., Dauvin, J.-C., Gentil, F. \& Salomon, J.-C. 2000. The influence of variability in larval dispersal on the dynamics of a marine metapopulation in the eastern Channel. Oceanologica Acta 23:423-442.

Exadactylos., A., Geffen, A.J., Panagiotaki, P. \& Thorpe, J.P. 2003. Population structure of Dover sole Solea solea: RAPD and allozyme data indicate divergence in European stocks. Marine Ecology Progress series 246:253-264.

Fonds, M. 1979. Laboratory observations on the influence of temperature and salinity on development of the eggs and growth of the larvae of Solea solea. Marine Ecology Progress Series 1:91-99.

Forward, R.B. \& Tankersley, R.A. 2001. Selective tidal-stream transport of marine animals. Oceanography and Marine Biology: Annual review 39:305-353.

Fox, C.J., Mccloghrie, P., Young, E.F. \& Nash, R.D.M. 2006. The importance of individual behaviour for successful settlement of juvenile plaice (Pleuronectes platessa L.): a modelling and field study in the eastern Irish Sea. Fisheries Oceanography 15:301-313.

Gibson, R.N. 1994. Impact of habitat quality and quantity on the recruitment of juvenile flatfishes. Netherlands Journal of Sea Research 32:191-206.

Gibson, R.N. 2005. Flatfishes : biology and exploitation. Blackwell Pub., Oxford UK.

Gilliers, C., Le Pape, O., Desaunay, Y., Morin, J., Guerault, D. \& Amara, R. 2006. Are growth and density quantitative indicators of essential fish habitat quality? An application to the common sole Solea solea nursery grounds. Estuarine, Coastal and Shelf Science 69:96-106.

Grioche, A., Harlay, X., Koubbi, P. \& Fraga Lago, L. 2000. Vertical migrations of fish larvae: Eulerian and Lagragian observations in the Eastern English Channel. Journal of Plankton Research 22:1813-1828.

Grioche, A., Koubbi, P. \& Harlay, X. 1999. Spatial patterns of ichthyoplankton assemblages along the Eastern English Channel French coast during spring 1995. Estuarine, Coastal and Shelf Science 49:141-152.

Hinrichsen, H.-H., Dickey-Collas, M., Huret, M., Peck, M.A. \& Vikebo, F.B. 2011. Evaluating the suitability of coupled biophysical models for fishery management. ICES Journal of Marine Science 68:1478-1487. doi: 10.1093/icesjms/fsr056.

Hinrichsen, H.-H., Kraus, G., Böttcher, U. \& Köster, F. 2009. Identifying eastern Baltic cod nursery grounds using hydrodynamic modelling: knowledge for the design of Marine Protected Areas. ICES Journal of Marine Science 66:101-108.

Hoch, T. \& Garreau, P. 1998. Phytoplankton dynamics in the English Channel: a simplified three dimensional approach. J Mar Sys 16.

Horwood, J. 1993. The bristol Channel Sole (Solea solea (L.)) : A fishery case study. Advance in Marine biology 29:215-367.

Houde, E. 2008. Emerging from Hjort's shadow. J Northw Atl Fish. Soc. 41:53-70.

Huret, M., Petitgas, P. \& Woillez, M. 2010. Dispersal kernels and their drivers captured with a hydrodynamic model and spatial indices: a case study on anchovy (Engraulis encrasicolus) early life stages in the Bay of Biscay. Progress in Oceonography 87:6-17.

Hurrel, J.W., van Loon, H. 1997. Decadal variations in climate associated with the North Atlantic Oscillation. Climatic Change, 36:301-326.

ICES. 2010. Report of the Working Group on the Assessment of the Demersal Stocks in the North Sea and Skagerrak. ICES CM 2010. 
Iles, T.C. \& Beverton, J.H. 2000. The concentration hypothesis: the statistical evidence. ICES Journal of Marine Science 57:216-227.

Juanes, F. 2007. Role of habitat in mediating mortality during the post-settlement transition phase of temperate marine fishes. Journal of Fish Biology 70:661-677.

Korotenko, K.A. \& Sentchev, A.V. 2008. Effects of particle migration on the features of their transport by tidal currents in a region of freshwater influence. Oceanology 48:622-633.

Kotthaus, A. 1963. Tagging experiments with the North Sea sole (Solea solea) in 1959 and 1960. Spec. Publ. Int. Commn. NW. Atlan. Fish:123-129.

Koutsikopoulos, C., Desaunay, Y., Dorel, D. \& Marchand, J. 1989. The role of coastal areas in the life history of sole (Solea solea L.) in the Bay of Biscay. Scientia marina 53:567-575.

Koutsikopoulos, C., Fortier, L. \& Gagne, J.A. 1991. Cross-shelf dispersion of dover sole (Solea solea (L.)) eggs and larvae in Biscay Bay and recruitment to inshore nursqeries. Journal of plankton research 13:923-945.

van der Land, M.A. 1991. Distribution of flatfish eggs in the 1989 egg surveys in the Southeastern North Sea, and mortality of plaice and sole eggs. Netherlands Journal of Sea Research 27:277-286.

Lazure, P. \& Dumas, F. 2008. An external-internal mode coupling for a 3D hydrodynamical model for applications at regional scale (MARS). Advances in Water Resources 31:233-250.

Levin, P.S. \& Stunz, G.W. 2005. Habitat triage for exploited fishes: can we identify essential fish habitat? Estuarine Coastal and shelf science 64:70-78.

Loots, C., Vaz, S., Planque, B. \& Koubbi, P. 2009. What controls the spatial distribution of the North Sea plaice spawning population? Confronting ecological hypotheses through a model selection framework. ICES Journal of Marine Science 67:244-257.

Lund, I., Steenfeldt, S.J., Suhr, K.I. \& Hansen, B.W. 2008. A comparison of fatty acid composition and quality aspects of eggs and larvae from cultured and wild broodstock of common sole (Solea solea L.). Aquaculture Nutrition 14:544-555.

Matheron, G. 1963. Principles of geostatistics. Economic Geology 58:1246-1266. doi: 10.2113/gsecongeo.58.8.1246.

Michel, S., Treguier, A.-M. \& Vandermeirsch, F. 2009. Temperature variability in the Bay of Biscay during the past 40 years, from an in situ analysis and a 3D global simulation. Continental Shelf Research 29:1070-1087. doi: 10.1016/j.csr.2008.11.019.

Le Pape, O. \& Bonhommeau, S. sub. Density-dependence and trophic limitation on coastal and estuarine nursery grounds for marine fishes. Ecological monographs.

Le Pape, O., Chauvet, F., Mahevas, S., Lazure, P., Guerault, D. \& Desaunay, Y. 2003. Quantitative description of habitat suitability for the juvenile common sole (Solea solea, L.) in the Bay of Biscay (France) and the contribution of different habitats to the adult population. Journal of Sea Research 50:139-149.

Pingree, R. 2005. North Atlantic and North Sea Climate Change: curl up, shut down, NAO and Ocean Coulour. Journal of Marine Biological Association 85:1301-1315.

Ramzi, A., Arino, O., Koutsikopoulos, C., Boussouar, A. \& Lazure, P. 2001a. Modelling and numerical simulations of larval migration of the sole (Solea solea (L.)) of the Bay of Biscay. Part 1: modelling. Oceanologica acta 24:101-112.

Ramzi, A., Arino, O., Koutsikopoulos, C., Boussouar, A. \& Lazure, P. 2001b. Modelling and numerical simulations of larval migration of the sole (Solea solea (L.)) of the Bay of Biscay. Part 2: numerical simulations. Oceanologica acta 24:113-124.

Rijnsdorp, A.D. \& Stralen, M. van. 1985. Selective tidal migration of plaice larvae (Pleuronectes platessa L. ) in the easter scheldt and the wesetrn waddensea:10pp.

Rijnsdorp, A.D., Van, B.F.A., Flatman, S., Millner, R.M., Riley, J.D., Giret, M. \& De Clerck, R. 1992. Recruitment of sole stocks, Solea solea (L.), in the northeast Atlantic. Netherlands Journal of Sea Research 29:173-192.

Rijnsdorp, A. \& Vingerhoed. 1994. Ecological significance of geographical and seasonal differences in egg size in sole solea solea (L.). Netherlands Journal of Sea Research.

Riou, P., Le Pape, O. \& Rogers, S.I. 2001. Relative contributions of different sole and plaice nurseries to the adult population in the Eastern Channel: application of a combined method using generalized linear models and a geographic information system. Aquatic Living Resources 14:125-135.

Rochette, S., Rivot, E., Morin, J., Riou, P. \& Le Pape, O. 2010. Effect of nursery habitat degradation on flatfish population: Application to Solea solea in the Eastern Channel (Western Europe). Journal of Sea Reseach 64:34-44.

Savina, M., Lacroix, G. \& Ruddick, K. 2009. Modelling transport of common sole larvae in the Southern North Sea: Influence of hydrodynamics and larval vertical movements. J Mar Sys. 
Sentchev, A. \& Korotenko, K. 2007. Modelling distribution of flounder larvae in the eastern English Channel: sensitivity to physical forcing and biological behaviour. Marine Ecology Progress Series 347:233-245.

Sentchev, A. \& Korotenko, K. 2005. Dispersion processes and transport pattern in the ROFI system of the eastern English Channel derived from a particle-tracking model. Continental Shelf Research 25:2294-2308.

van der Veer, H., Bergham, R., Miller, J. \& Rijnsdorp, A. 2000. Recruitment in flatfish, with special emphasis on North atlantic species: Progress made by the Flatfish Symposia. Ices Journal of Marine Science 57:202-215.

Walsh, M., Skogen, M., Reid, D.G., Svendsen, E. \& McMillan, J.A. 1996. The relation ship between the location of western mackerel spawning, larval drift and recruit distributions: a modelling study. $12 \mathrm{p}+$ annexes.

Werner, F.E., Quinlan, J.A., Blanton, B.O. \& Luettich, R.A.J. 1997. The role of hydrodynamics in explaining variability in fish populations. Journal of Sea Research 37:195-212. 


\section{Figures.}

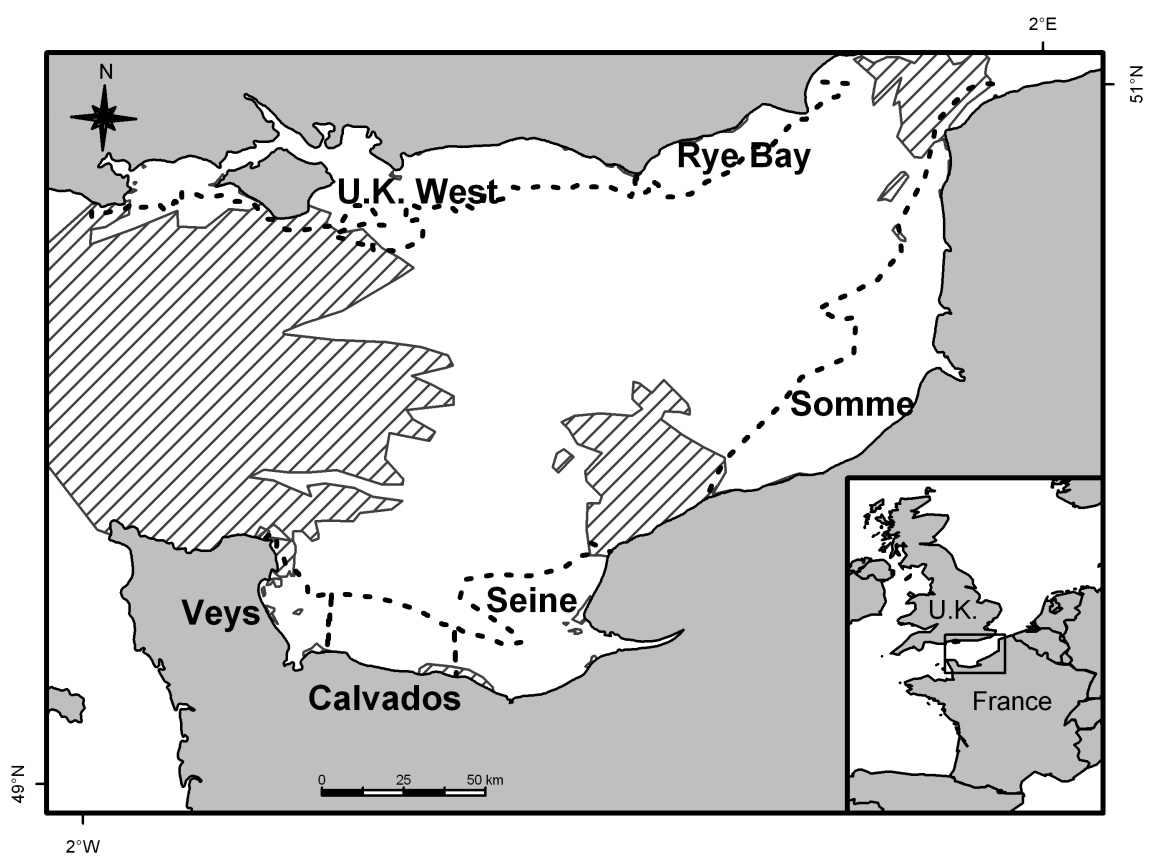

Fig. 1. The eastern Channel divided in 6 different coastal nursery sectors, limited by the $25 \mathrm{~m}$ isobath (dotted lines). Light grey: continent; hatched areas: pebbles and rocks. Lower right corner: general location of the study site

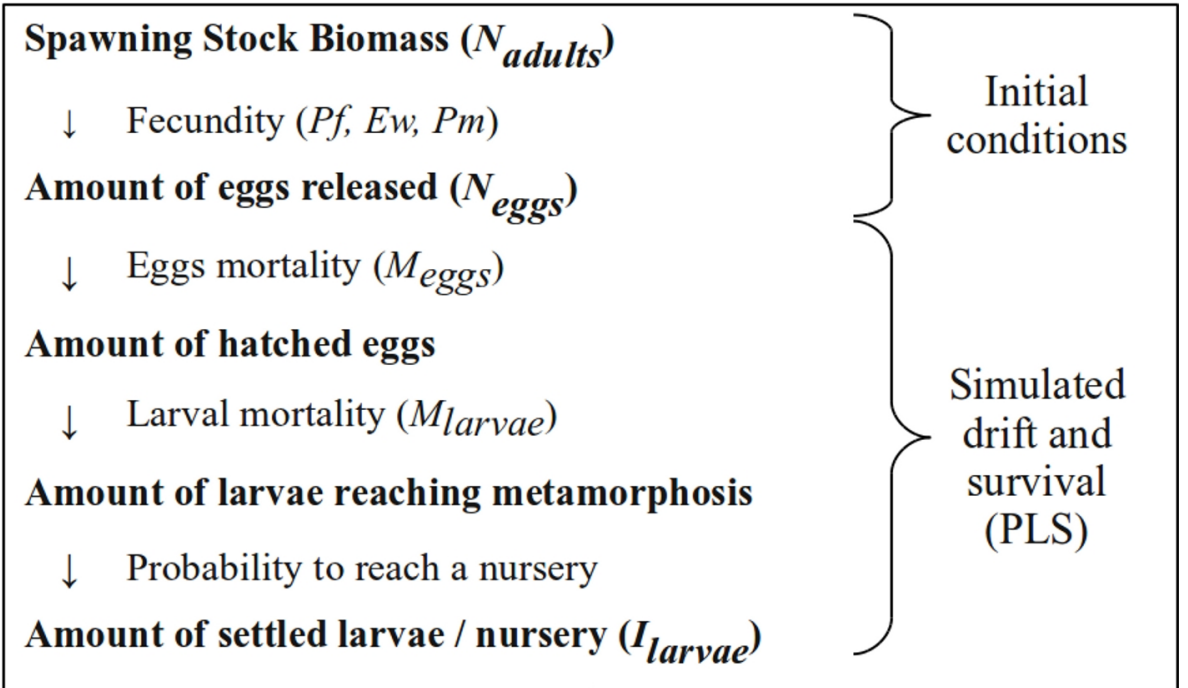

Fig. 2. Chart flow for the development of early life stages during the transport 

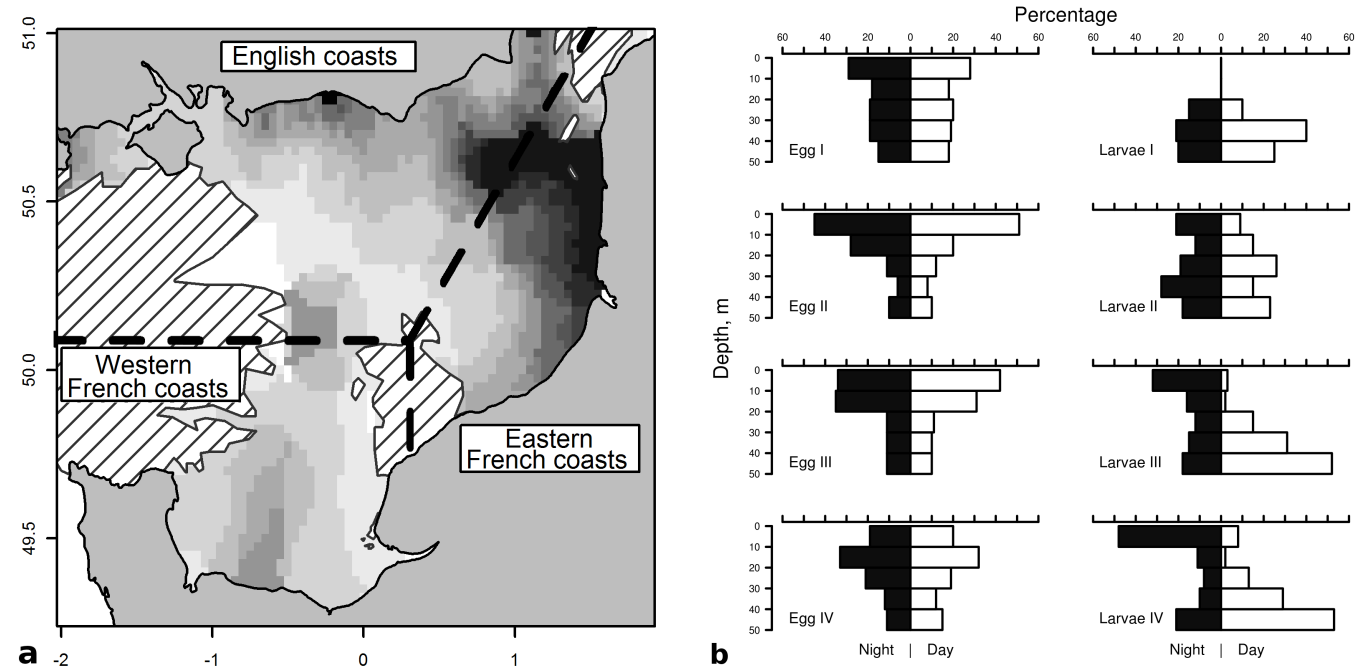

Fig. 3. Distribution of eggs and larvae. (a) Kriged distribution of means of 1-day egg densities, averaged over the spawning period, interpolated from the 1991 egg survey (Anon., 1992). The darker, the denser. Hatched areas: pebbles, no spawning. Dashed lines: limits of the three spawning sub-areas. (b) Vertical distribution of sole eggs and larvae observed in scientific campaigns in the Bay of Biscay (see Koutsikopoulos et al., 1991).

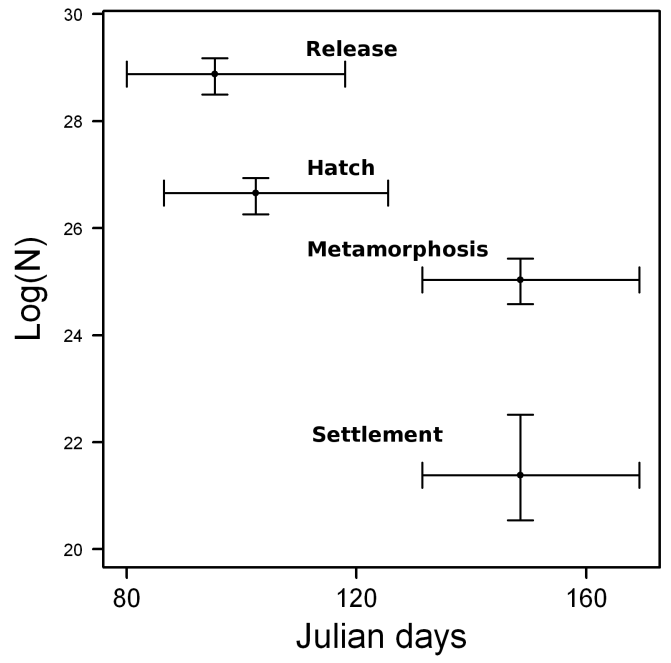

Fig. 4. Simulated cohort decline from the biophysical model. Error-bars represent the interannual variability, with minimum and maximum values (at each stage, horizontal lines represent the variability of the spawning peak and vertical lines the variability of the number of eggs / larvae). 


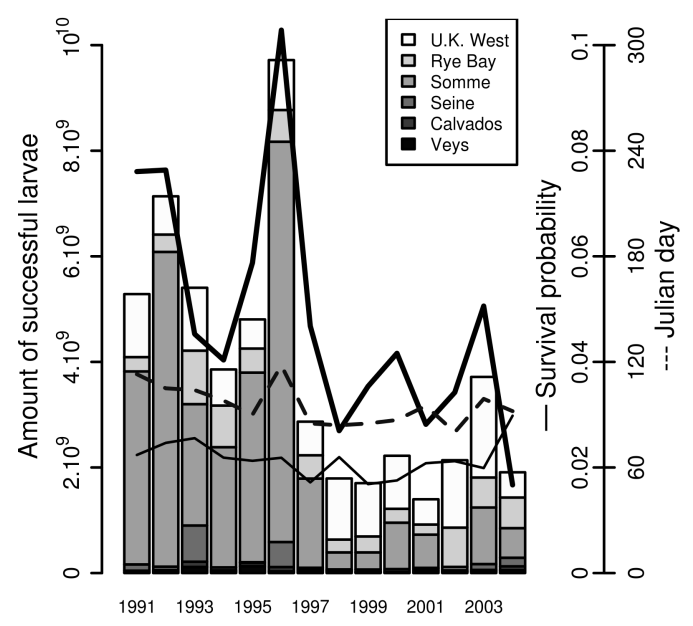

Fig. 5. Left axis: barplot: interannual variability of the larval supply distributed among nurseries. Right axis: Dashed line: date of the spawning peak (in Julian day). Thin line: survival of particles between spawning and metamorphosis (wherever metamorphosis occured). Bold line: probability to survive to metamorphosis (i.e. Metamorphosis over a nursery).

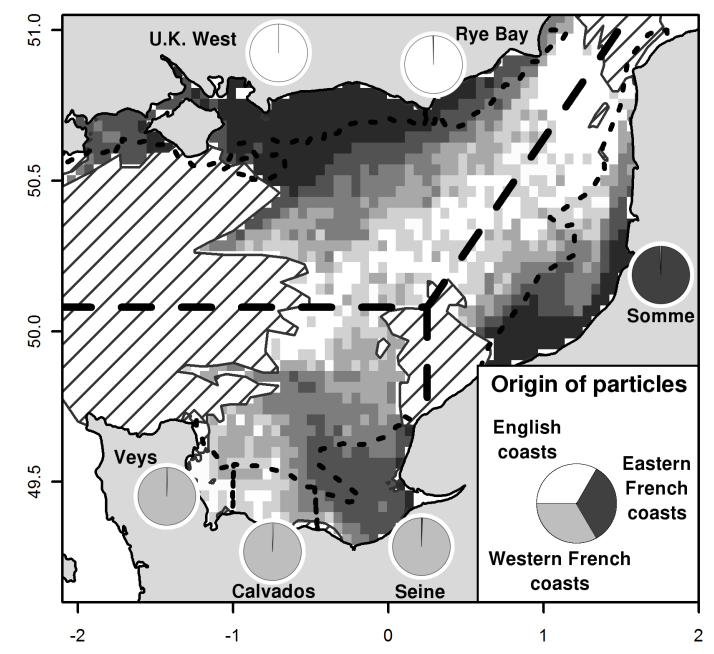

Fig. 6. Connectivity from spawning to nursery areas for the entire studied period (19912004). For each pixel in the grid, the color represents the mean probability, averaged on all simulated years, of successfull settlement on a nursery of the eastern Channel for a particle released from this point (PLS map, Daewel et al., 2011). The darker, the higher probability. Hatched areas: pebbles, no spawning. Dashed lines: limits of the three spawning sub-areas. Pies: origin of larvae settling over a nursery (proportions of larvae from the three spawning areas). 
Table 1. Sensitivity of larval supply to spawning and drift history: comparison with the baseline scenario. Mean bias: the difference of the number of successful larvae in each scenario relative to the baseline scenario (averaged over the 1994-2001 time series). $\mathrm{R}^{2}$ : the coefficient of linear correlation of the time series of larval supply in each scenario against the baseline scenario. Main differences ( $>20 \%$ arbitrarily) are underlined. Pop. : Population scale. Calva.: Calvados.

\begin{tabular}{|c|c|c|c|c|c|c|c|c|}
\hline Scenario & Indicator & Pop. & U.K. West & Rye Bay & Somme & Seine & Calva. & Veys \\
\hline \multirow[t]{2}{*}{$M_{\text {larvae }}=0.03 \mathrm{day}^{-1}$} & Mean bias & $+50 \%$ & $+51 \%$ & $+53 \%$ & $+50 \%$ & $+42 \%$ & $+51 \%$ & $+52 \%$ \\
\hline & $\mathrm{R}^{2}$ & $\sim 1$ & $\sim 1$ & $\sim 1$ & 1 & 1 & 0.99 & $\sim 1$ \\
\hline \multirow[t]{2}{*}{$M_{\text {larvae }}=0.05 \mathrm{day}^{-1}$} & Mean bias & $-32 \%$ & $-33 \%$ & $-34 \%$ & $-32 \%$ & $-29 \%$ & $-33 \%$ & $-33 \%$ \\
\hline & $\mathrm{R}^{2}$ & $\sim 1$ & $\sim 1$ & $\sim 1$ & $\sim 1$ & 1 & 0.99 & 0.99 \\
\hline \multirow[t]{2}{*}{$\begin{array}{l}\text { No peak of spawning: } \\
W_{\text {time }}\left[y, t_{r}\right]=\text { constant }\end{array}$} & Mean bias & $-4 \%$ & $1 \%$ & $0 \%$ & $+3 \%$ & $+78 \%$ & $+23 \%$ & $+7 \%$ \\
\hline & $\mathrm{R}^{2}$ & 0.96 & $\underline{0.76}$ & 0.85 & 0.99 & 0.85 & 0.91 & 0.80 \\
\hline \multirow[t]{2}{*}{$\begin{array}{l}\text { Constant SSB: } \\
N_{\text {eggs }}[y]=\text { constant }\end{array}$} & Mean bias & $+3 \%$ & $+1 \%$ & $-2 \%$ & $0 \%$ & $+73 \%$ & $+21 \%$ & $+9 \%$ \\
\hline & $\mathrm{R}^{2}$ & 0.94 & 0.84 & 0.84 & 0.97 & 0.99 & 0.89 & 0.93 \\
\hline \multirow{2}{*}{ 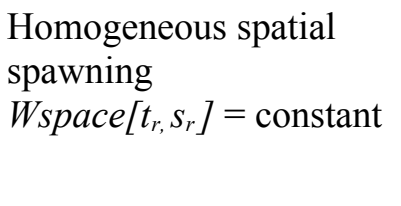 } & Mean bias & $-1 \%$ & $+31 \%$ & $+61 \%$ & $-52 \%$ & $+203 \%$ & $+69 \%$ & $+61 \%$ \\
\hline & $\mathrm{R}^{2}$ & 0.86 & 0.97 & 0.94 & 0.98 & 0.93 & 0.90 & 0.93 \\
\hline \multirow[t]{2}{*}{$\begin{array}{l}\text { PLS map used for spatial } \\
\text { spawning }\end{array}$} & Mean bias & $+242 \%$ & $+400 \%$ & $+323 \%$ & $+148 \%$ & $+312 \%$ & $+48 \%$ & $+25 \%$ \\
\hline & $\mathrm{R}^{2}$ & 0.88 & 0.90 & 0.81 & 0.91 & 0.89 & $\underline{0.69}$ & $\underline{0.79}$ \\
\hline
\end{tabular}

